\title{
Matrix approach to managing of rationing in the public procurement
}

\author{
Yevgenia Stroganova ${ }^{1 *}$, Niyaz Kadyrov ${ }^{1}$, and Alexander Prokhorov ${ }^{1}$ \\ ${ }^{1}$ Moscow State Institute of International Relations (MGIMO University), Prospect Vernadskogo, 76, \\ 119454 Moscow, Russia
}

\begin{abstract}
The article analyzes the potential for improving rationing in the public procurement system to increase their transparency and efficiency. An original method of procurement rationing based on a matrix approach to management is proposed. The methodology includes a combination of mathematical methods, scenario and predictive methods, which allows us to take into account the alternative solutions in procurement management. The fundamental principle of applying the matrix approach in procurement is not to optimize the procedures within a specific order, not to save budget funds as such, but to increase the efficiency of procurement planning in order to implement the entire set of projects, taking into account the factors of time, the need for procurement for the customer and public interests.
\end{abstract}

\section{Introduction}

Today, procurement management in the public sphere is considered as a set of public relations that develop between the state and the subjects of the country's economic system. Ensuring the effectiveness and efficiency of this interaction requires a qualitative legislative development of the components of bilateral competitiveness between the participating parties [1].

Public procurement is a historically established and traditional type of activity, it is the process of purchasing activities for public needs that allows us to meet the urgent needs of society in various goods and services [2]. An important factor is the use of public funds, so it is necessary to improve the efficiency of their use in public procurement.

Conducting such purchases has a positive impact on the development of the state itself and on the development of business in general [3,4]. The state, represented by state and municipal customers, receives the goods (work or service) it needs on the most favorable terms, and the supplier receives money.

Each country organizes its own system of public procurement [5]. Thus, the "value for money" principle is used as a comparison of the final cost and the recommended one [6], as well as a combination of price, technical benefit and quality [7]. It is important to follow the concept of efficient spending - this is a certain requirement for procurement officials to achieve the best results at each stage of the procurement process, taking into account not only the lowest price, but also the benefits and costs based on the life cycle of goods.

\footnotetext{
* Corresponding author: yevgenias@bk.ru
} 
National laws orders for works, supplies and services provide for control over public expenditures at all stages of procurement activities [8]: decision-making; calculation of cost estimates; analysis of the compliance of planned expenditures with budget capabilities; control of contract payments.

Competition among suppliers is also important for the effective functioning of the procurement system - which is why countries strive to develop a public procurement system with a large number of responsible participants [9].

Support for national companies and entrepreneurs is also included in the system of public procurement decisions. Public procurement is a tool to reduce the technological and financial dependence of national production on foreign sources of resources and capital [10]. Countries seeking to increase global competitiveness [11] define public procurement as a mechanism to support exports [12]. This approach contributes to a high level of production workload, avoids unemployment, and develops innovations [13] and cooperative interactions in industry [14]. The modern system of public procurement is also focused on achieving the goals of sustainable development, including the green economy [15].

Most national public procurement management systems are aimed at optimization while minimizing costs; ensuring equal conditions of competition when entering into a contract [16]; compliance with the requirements of publicity; promoting fair and open business [17]; helping small and medium-sized enterprises to obtain government orders [18].

Conditionally, the public procurement process can be divided into three stages: planning; procurement implementation; monitoring, audit and control. For the purposes of our study, it is important to distinguish two key elements in planning-justification and rationing. The features of national contract systems are considered to be the large-scale application of planning methods to meet public needs, price monitoring, databases of standard contracts, control mechanisms and procedures for evaluating the results of their execution, and specialized information resources for managing contract systems.

The justification by the customer is the process of determining the compliance of the planned purchase with the objectives of the procurement by forming a procurement plan and a procurement schedule. When forming a procurement plan, the object of purchase, product requirements and standard costs are subject to justification. When forming the schedule, the initial (maximum) price of the contract, the price of the contract concluded with a single supplier (contractor, contractor) and the method of determining the supplier are subject to justification. The evaluation of the validity of procurement is carried out during monitoring, audit and control. Control over compliance with the requirements for the justification of procurement and the validity of procurement is carried out by special organizations of the internal state financial control and antimonopoly agencies - for example, in Russia, this is the Federal Antimonopoly Service.

Each state has its own system of public procurement management. For example, in Russia there is legislation on the contract system in the procurement of goods, works, and services to meet state and municipal needs. In accordance with the law, the planning and procurement activities themselves must be carried out taking into account the requirements for the goods, works, services purchased by the customer and standard costs. By setting the quantity and price standards within the framework of determining the standard costs, it becomes possible to determine the reasonable volume and maximum cost of goods, works, and services planned for procurement.

The objective function of procurement rationing is to establish a balance between the interests of the customer in meeting his objective needs and ensuring the interests of the state and society in terms of saving budget funds from unnecessary expenses, as well as inefficient spending on products with excessive consumer properties or luxury goods. 
The tools for implementing this function are a set of requirements for the form of procurement plans, procurement schedules, the procedure for their formation, approval and maintenance in a single information system. The implementation of these measures made it possible to significantly unify the contract system, systematize the activities of customers and commercial structures, and increase the transparency of the procurement sector.

\section{Materials and methods}

The study contains the use several methods that allow us to more accurately reveal the mechanism of rationing in the public procurement. At the same time, this mechanism fully complies with legal restrictions, but allows to increase the efficiency and transparency of the procurement management system itself.

For this purpose, the Hurwicz Criterion calculation method [19] is used, which is apply to make decisions under uncertainty. There is an uncertainty factor for procurement management, so it is reasonable that making a decision is a choice of alternative solutions. The procurement management system should have a requirement that the choice will be determined as a weighted average between the best and worst possible payoff for each solution alternative (among all possible procurement parameters for that particular alternative) and then as the solution that has the maximum weighted average. Thus, this method takes into account the pessimistic criterion, but is more focused on the average position of choice. The authors also took into account the mathematical modifications of this method published in the works of leading experts in the analysis of the sensitivity of decisions in the form of a decision tree [20], in the selection of investment projects [21] and in the analysis of competition [22].

The authors implement the possibility of implementing the selected scenario with certain parameters using the matrix method that take into account the factors of SWOTanalysis (analysis of strengths and weaknesses, analysis of opportunities and threats of the external environment). This method is used in strategic management and characterized by the greatest adaptability and flexibility, integrating vertical resource management and horizontal management of specific purchases.

\section{Results and discussion}

The process of procurement rationing is presented as a certain sequence of actions, including mandatory SWOT-analysis. The authors also suggest taking into account the possibility of including the design of procurement scenarios, as well as the construction of a procurement matrix. These actions should follow the author's methodology for rationing purchases based on the matrix approach to management (fig. 1). 


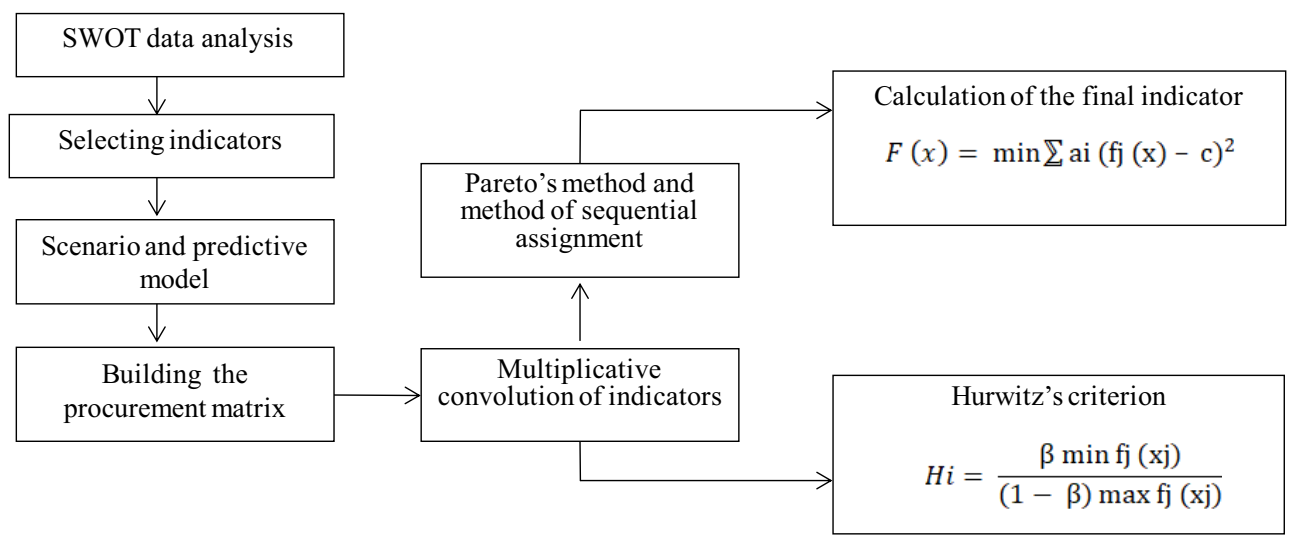

Fig. 1. Methodology of procurement rationing.

During the first stage, it is necessary to identify and highlight the main economic and social tasks and problems. The authors conducted a SWOT-analysis of social and economic development to select the key indicators of the system of procurement rationing. The results of this analysis are presented in tables 1 and 2.

Table 1. SWOT-analysis of economic development.

\begin{tabular}{|c|c|}
\hline $\begin{array}{l}\text { Strengths } \\
\text { - high development potential; } \\
\text { - synergetic effect of interaction of } \\
\text { economic entities. }\end{array}$ & \begin{tabular}{l}
\multicolumn{1}{c}{ Weaknesses } \\
- lack of high-tech projects; \\
- insufficient level of competitiveness; \\
- investment attractiveness.
\end{tabular} \\
\hline $\begin{array}{l}\text { Development aspects } \\
\text { - improving the regulatory framework; } \\
\text { - improving the quality of services; } \\
\text { - increase the level of competitiveness. }\end{array}$ & \begin{tabular}{l}
\multicolumn{1}{c}{ Possible problems } \\
- financial risks; \\
- social risks; \\
- low efficiency of management.
\end{tabular} \\
\hline
\end{tabular}

Table 2. SWOT-analysis of social development.

\begin{tabular}{|c|c|}
\hline $\begin{array}{l}\text { Strengths } \\
\text { - availability of affordable education; } \\
\text { - extensive experience in the field of social and } \\
\text { economic development }\end{array}$ & $\begin{array}{l}\text { Weaknesses } \\
\text { - lack of qualified personnel; } \\
\text { - insufficient information knowledge. }\end{array}$ \\
\hline $\begin{array}{l}\text { Development aspects } \\
\text { - professional development; } \\
\text { - innovation and investment; } \\
\text { - continuous monitoring of the level of efficiency. }\end{array}$ & $\begin{array}{l}\text { Possible problems } \\
\text { - lack of development of the } \\
\text { information and social basis. }\end{array}$ \\
\hline
\end{tabular}

The SWOT-analysis was based on the requirements for the subjects of interaction in the procurement, and objective external and internal factors that form the corresponding infrastructure that accompanies the procurement process.

The second stage is the selection of indicators for procurement rationing. The basis of procurement activity remains the restriction of funding allocated to state or municipal needs. Therefore, one of the priority areas for improving procurement activities is to expand the range of objects and rationing principles based on the assessment of the composition and type of regulatory costs. Author's research led to the following list of regulatory costs:

- expenditures on the creation of the state reserve in the defense industry; 
- communication and information development costs;

- expenses for research and engineering activities;

- defense, national security, and law enforcement spending;

- expenses for the repair of state property;

- expenses for additional education of employees;

- technical development, reconstruction and construction expenses;

- other expenses for the fulfillment of municipal obligations to citizens.

Based on expert assessments, it is concluded that the following expenses are currently the most important:

- to ensure reconstruction and construction;

- for communication and information support;

- to improve the level of qualification of employees;

- for major repairs.

At the third stage, the results of the SWOT-analysis are used for inclusion in a special forecasting model for solving the problem of procurement rationing (fig. 2).

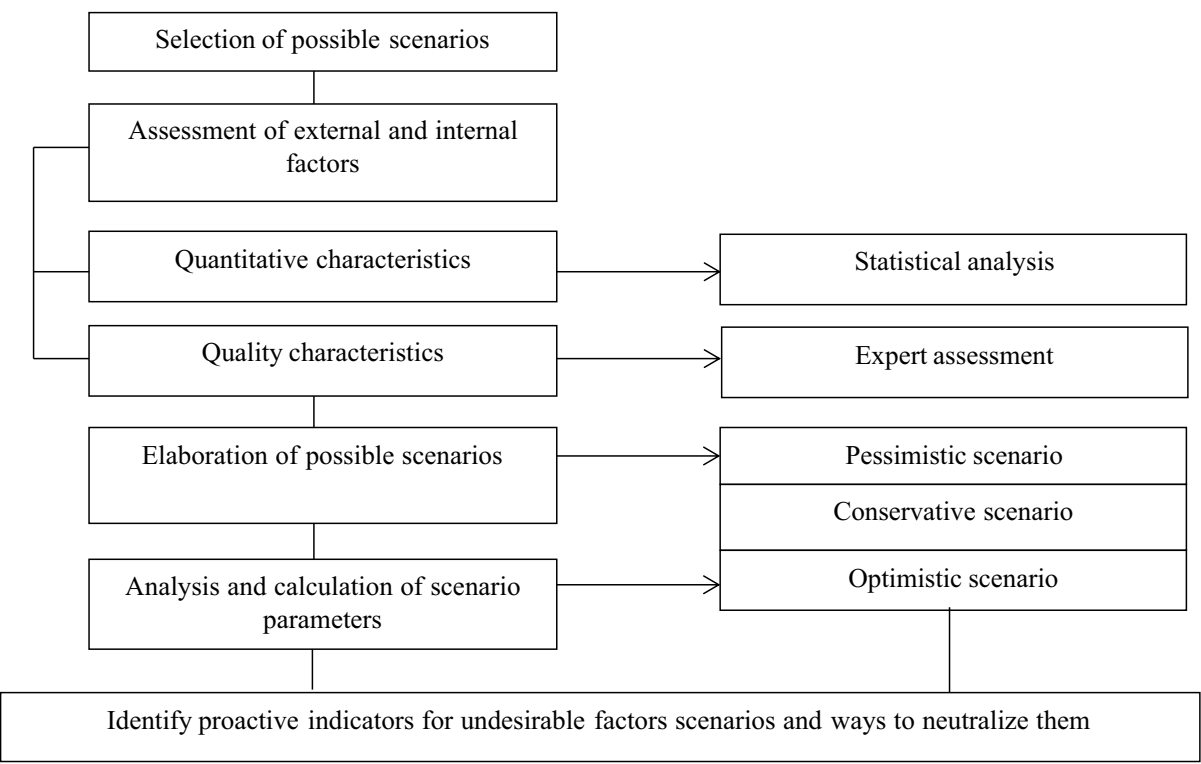

Fig. 2. Scenario and predictive model of procurement rationing.

The implementation of the proposed scenario and forecast model of procurement rationing is based on the definition of the appropriate mathematical apparatus. The dynamic models used are based on the selection of parameters of procurement objects. Probabilistic scenarios are formed on the basis of statistical analysis of time series.

The effectiveness of the management of the public procurement rationing depends on the combination of internal and external factors that affect the planning and implementation of procurement. The management of the city's procurement rationing process is aimed at maximizing the risk reduction in the preparation of procurement documentation.

Scientific developments in the field of procurement management can be implemented through the use of management tools for strategic planning. Planning is a work aimed at the dynamic development of society as a whole, determining the basic economic parameters in the near future and in the future.

In the process of rationing, the normative method is used to take into account quantitative indicators, such as the marginal price, the norms of positivity and the analytical method of taking into account the qualitative characteristics of consumer properties of 
products, goods and services, as well as their further comparison. Methods of behavioral optimization and decision optimization are quite rare, since the feasibility of its application directly depends on the need for model optimization during a particular purchase. The analysis of procurement practices showed that the level of professionalism of the customer is insufficient for the development and implementation of optimization models in the field of procurement rationing.

Promising program-resource and program-target methods used, for example, in Russia in the implementation of national projects, are limited due to their basis in the form of a resource or target component. For the purposes of the study, the authors improve the selected methods based on the matrix approach to normalization.

At the fourth stage, we will consider the possibility of implementing a matrix approach to procurement rationing.

Using different management methods in the of procurement, managers need to quickly respond to changing external and internal conditions, while ensuring the efficient use of labor and material resources. Procurement rationing with this approach allows you to regulate the procurement system according to key criteria: financial security and the need for purchases (fig. 3).

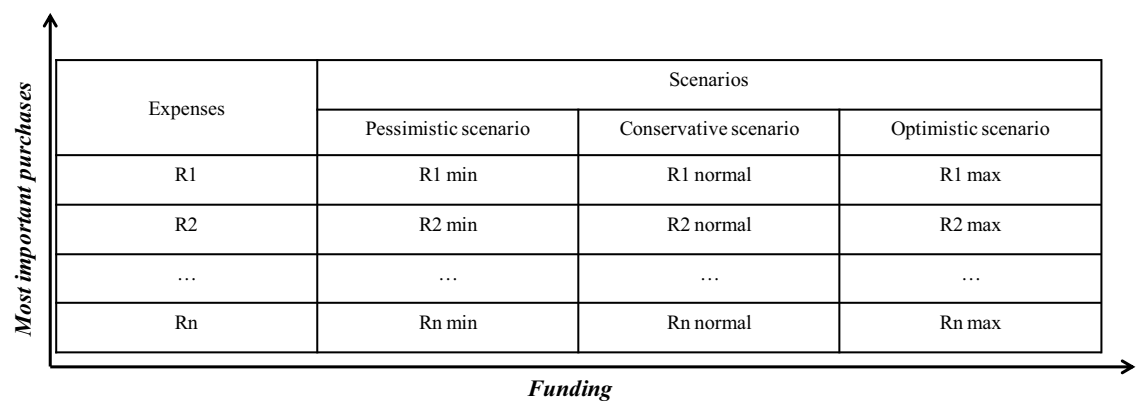

Fig. 3. Matrix for managing the procurement rationing process.

Thus, in procurement rationing, the matrix structure is an overlay of the project structure by type of expenditure on the distribution of management funding.

The fundamental principle of applying the matrix approach in procurement is not to optimize the procedures within a specific order, not to save budget funds as such, but to increase the efficiency of procurement planning in order to implement the entire set of projects, taking into account the factors of time, the need for procurement for the customer and the state interests.

This matrix is based on a diagonal pattern, which consists in the fact that the most effective use of budget funds in procurement involves moving along the diagonal of the matrix from the lower left corner to the upper right corner. In the implementation of such development, a high level of satisfaction, for example, of the needs of the city, corresponds to the minimum levels of funding. Conversely, needs that are sufficiently met are currently deferred until funding improves.

The implementation of the matrix management system in the rationing process will allow integrating various types of activities within the framework of implemented programs, taking into account regulatory costs in the context of classification groups and procurement requirements in the rationing process, and involving managers at various levels for the purposes of procurement activities.

The main obstacle in the transition to the matrix approach in the procurement rationing is the complexity, which requires a high level of corporate culture and a developed strategic 
thinking of managers. In addition, managers quickly identify and eliminate duplication of functions, and maintain the effectiveness of the system at a certain level.

This matrix structure is most effective during periods of economic stability, when funding for all projects is sufficient. In times of crisis, appropriate skills and experience in making managerial decisions are needed to maintain efficiency.

The next step is to bring the obtained values to comparable data.

For research's purposes, we will evaluate the quality of the solutions used by the management based on the multiplicative convolution of the obtained indicators. The final evaluation of the procurement activity consists of private assessments for all contracts concluded and the customer's needs met. In this case, the form of the function $f(x)$ is determined by how one can represent the contribution of each particular criterion $\mathrm{fj}(\mathrm{x})$ to the general quality criterion. Taking into account the requirement of comparability of particular criteria, the calculation of the global criterion by means of multiplicative convolution is performed according to the equation:

$$
F(x)=\prod_{\mathrm{j}=1}^{\mathrm{i}} \mathrm{fj}(\mathrm{x})
$$

The disadvantage of this method is the disparity in the importance of some expenses. As a result, low values for the most important indicators and high values for secondary costs can give a good final result, but this does not mean that this solution is optimal. To eliminate this disadvantage, it is advisable to use weighted convolutions of particular performance criteria. To develop our forecast-scenario model based on the matrix approach, we apply the Hurwitz criterion (pessimism-optimism criterion). This method will allow you to determine a fair intermediate option between extremely pessimistic and optimistic options using the equation:

$$
H i=\frac{\beta \min \mathrm{fj}(\mathrm{xj})}{(1-\beta) \max \mathrm{fj}(\mathrm{xj})}
$$

$\beta(0 \leq \beta \leq 1)$ is the "optimism - pessimism coefficient".

At $\beta=1$, the estimate becomes the minimum, and at $\beta=0$, it is the most optimistic.

The value of $\beta$ is determined by the manager. The final indicator is calculated using the equation:

$$
F(x)=\min \sum a i(\mathrm{fj}(\mathrm{x})-\mathrm{c})^{2},
$$

And:

- ai is the weight coefficients;

- $c$ is the fixed value of the criterion $f(x i)$, for example, its average value;

- $\mathrm{f}(\mathrm{xi})$ is private $\mathrm{i}$-th performance indicator;

- $\mathrm{fj}(\mathrm{xi})$ is a private $\mathrm{i}$-th indicator of the effectiveness of the $\mathrm{j}$-th project.

To perform the convolution of indicators, it is necessary to normalize the indicators or use weight coefficients to take into account the importance and dimension. Take into account the nature of the relationships between the indicators and the specifics of a particular task, choose the type of convolution.

The authors note that the complexity of the model implementation is determined by the adequacy of the distribution of weight coefficients. Also, the disadvantage of the generalized criterion is expressed in the impossibility of taking into account the hierarchical dependence of the resulting indicator on the values of particular indicators. 
Taking into account the above, we will confirm the obtained result by means of a multicriteria evaluation of alternatives to the solution based on Pareto selection rules. In this case, priority is given to projects for which there is no better alternative for at least one criterion and no worse for others. In general, this leads to the solution of a multi-criteria problem by the successive assignments method, when the optimal solution is consistently found for each of the criteria ordered by importance, with the assignment of a value for each of the criteria optimized at the previous step by the manager at each step of solving the assignment problem.

The use of the matrix approach in the public procurement rationing in one of the large Russian cities has led to the following results:

- at the stage of need's justification and the formation of procurement plans - costs were reduced by $6 \%$;

- at the stage of examination of the initial (maximum) contract prices - costs were reduced by $14 \%$;

- at the stage of direct holding of open and competitive tenders - costs were reduced by $11 \%$.

The most significant savings (project expertise) were achieved through the selection of scenarios based on the successful solution of three interrelated tasks: a) budget savings by reducing contract prices; b) maximum approximation of the price of the state contract to the market price; c) application of an additional mechanism in relation to competition during tenders.

\section{Conclusions}

The effectiveness of procurement activities is derived from the quality of planning and decision-making management. The basis for building a competent procurement plan is the accuracy and consistency of the characteristics of the objects of procurement, the detail of the most important tasks and procedures, and the time of receiving products, providing services, and performing work.

Procurement rationing is part of the procurement planning process. If the cost rationing corresponds to the procurement plan, then the rationing of the requirements for the purchased products corresponds to the schedule. Based on the standard costs, the procurement is justified and proposals for the draft budget are prepared and a procurement plan is drawn up. Based on the normalization of requirements for certain types of goods, works, and services established at the legislative level by the relevant lists, a schedule is prepared, and procurement documents (notification, documentation) are developed.

The final indicator obtained by the authors in this article will allow us to normalize expenditures taking into account the allocated budget funds for purchases and distribute them on the basis of a matrix approach in order to achieve maximum budget efficiency.

The methodology proposed by the authors makes it possible to conduct procurement rationing on the basis of monitoring the social and economic development of the city, ensuring maximum efficiency of interaction between state authorities and commercial structures. This allows you to achieve the goals and implement the activities provided for by state programs, fulfill international obligations, and perform the functions and powers of state bodies.

\section{References}

1. E. Bosio, S. Djankov, E.L. Glaeser, A. Shleifer, NBER Working Paper, 27188 (2020). https://doi.org/10.3386/w27188. 
2. L. Montalbán-Domingo, T. García-Segura, M. A. Sanz, E. Pellicer, Journal of Cleaner Production, 198, 1355-1371 (2018). https://doi.org/10.1016/j.jclepro.2018.07.083

3. I. Stepnov, J. Kovalchuk, E. Gorchakova, I. Izvestiya Vysshikh Uchebnykh Zavedenii, Seriya Teknologiya Tekstil'noi Promyshlennosti, 3, 268-272 (2018)

4. D. Stapran, I. Stepnov, Sourcing and Digital Strategies Performance of Big Companies in Key Global Markets (2021). https://doi.org/10.1007/978-3-030-58267-8_7

5. A.S. Patrucco, D. Luzzini, S. Ronchi, Journal of Public Procurement, 17(2), 229-269 (2017). https://doi.org/10.1108/JOPP-17-02-2017-B003

6. P. Adjei-Bamfo, T. Maloreh-Nyamekye, A. Ahenkan, Resources, Conservation and Recycling, 142, 189-203 (2019). https://doi.org/10.1016/j.resconrec.2018.12.001

7. A. Rhode, Public Procurement in the European Union (2019)

8. V. Lember, R. Kattel, T. Kalvet, Public Procurement, Innovation and Policy (2014)

9. A. Flynn, Policy Studies, 39(4), 422-443 (2018) https://doi.org/10.1080/01442872.2018.1478406

10. J. Kovalchuk (eds), Post-Industrial Society (2020)

11. I. Stepnov (eds), Technology and Business Strategy (2021)

12. R. Kattel, V. Lember, Journal of Public Procurement, 10(3), 368-404 (2010)

13. E. Uyarra, J.M. Zabala-Iturriagagoitia, K. Flanagan, E. Magro, Research Policy, 49(1), 103844 (2020). https://doi.org/10.1016/j.respol.2019.103844

14. I. Stepnov, J. Kovalchuk, E. Gorchakova, Studies on Russian Economic Development, 30(3), 346-354 (2019). https://doi.org/10.1134/S107570071903016X

15. S.D. Sönnichsen, J. Clement, Journal of Cleaner Production, 245, 118901 (2020) https://doi.org/10.1016/j.jclepro.2019.118901

16. K.V. Thai, International Public Procurement (2015)

17. F. Decarolis, M. Frey, Public Procurement's Place in the World (2014)

18. J. Saastamoinen, H. Reijonen, T. Tammi, Technovation, 69, 2-14 (2018) https://doi.org/10.1016/j.technovation.2017.10.003.

19. L. Hurwicz, The generalized Bayes minimax principle: a criterion for decision making under uncertainty, Discussion Paper Statistics, 335, Cowles Commission, 1-7 (1951)

20. B. Kaminski, M. Bogumil, P. Szufel, Central European Journal of Operations Research, 26, 135-159 (2018). https://doi.org/10.1007/s10100-017-0479-6

21. H. Gaspars-Wieloch, Central European Journal of Operations Research, 22, 779-794 (2014). https://doi.org/10.1007/s10100-013-0302-y

22. A. Zapata, M.A. Caraballo, L. Monroy, Central European Journal of Operations Research, 27, 937-952 (2019). https://doi.org/10.1007/s10100-017-0517-4 